\title{
Methylene Blue Inhibits In Vitro the SARS-CoV-2 Spike - ACE2 Protein-Protein \\ Interaction - A Mechanism That Can Contribute to Its Antiviral Activity Against
}

COVID-19

Damir Bojadzica , Oscar Alcazara , and Peter Buchwald*a,b

${ }^{\mathrm{a}}$ Diabetes Research Institute and ${ }^{\mathrm{b}}$ Department of Molecular and Cellular Pharmacology, Miller School of Medicine, University of Miami, Miami, Florida, USA

*Corresponding Author: Phone: 305 243-9657, pbuchwald@med.miami.edu, Diabetes Research Institute, Miller School of Medicine, University of Miami, 1450 NW 10 Ave, Miami, FL 33136, USA. 


\begin{abstract}
Due to our interest in the chemical space of organic dyes to identify potential small-molecule inhibitors (SMIs) for protein-protein interactions (PPIs), we initiated a screen of such compounds to assess their inhibitory activity against the interaction between SARS-CoV-2 spike protein and its cognate receptor ACE2, which is the first critical step initiating the viral attachment and entry of this coronavirus responsible for the ongoing COVID-19 pandemic. As part of this, we found that methylene blue, a tricyclic phenothiazine compound approved by the FDA for the treatment of methemoglobinemia and used for other medical applications (including the inactivation of viruses in blood products prior to transfusion when activated by light), inhibits this interaction. We confirmed that it does so in a concentration-dependent manner with a low micromolar half-maximal inhibitory concentration $\left(\mathrm{IC}_{50}=3 \mu \mathrm{M}\right)$ in our protein-based ELISA-type setup, while chloroquine, siramesine, and suramin showed no inhibitory activity in this assay. Erythrosine B, which we have shown before to be a promiscuous SMI of PPIs, also inhibited this interaction with an activity similar, possibly slightly higher, than those found for it for other PPIs. This PPI inhibitory activity of methylene blue could contribute to its antiviral activity against SARS-CoV-2 even in the absence of light by blocking its attachment to ACE2-expressing cells and making this inexpensive and widely available drug potentially useful in the prevention and treatment of COVID-19 as an oral or inhaled medication.
\end{abstract}

Keywords: ACE2, antiviral, chloroquine, COVID-19, methylene blue, protein-protein interaction, SARSCoV-2, spike protein. 


\section{INTRODUCTION}

Severe acute respiratory syndrome-coronavirus 2 (SARS-CoV-2), a novel betacoronavirus and the most recent one of the seven coronaviruses (CoVs) known to infect humans, is responsible for COVID-19, which has been declared a pandemic by the World Health Organization in March 2020 and continues to spread worldwide (Liu et al., 2020; Matheson and Lehner, 2020; Moore and June, 2020). While four CoVs (HCoV 229E, OC43, NL63, and HKU1) are responsible for about one third of the common cold cases in humans, three have caused recent epidemics associated with considerable mortality: SARS-CoV-1 (20022003, causing 10\% mortality), MERS-CoV (Middle East respiratory syndrome coronavirus; 2012, causing 35\% mortality), and now SARS-CoV-2 (2019-2020), which seems to be less lethal but more transmissible (Guy et al., 2020). COVID-19 is the most infectious agent in a century (Tiwari et al., 2020) and has already caused infections in the order of tens of millions and deaths that are likely to be in the order of millions worldwide. According to current early estimates, about $3 \%$ of infected individuals need hospitalization and $0.5 \%$ die, a range that is strongly age-dependent increasing from $0.001 \%$ in $<20$ years old to $8.3 \%$ in those $>80$ years old (Salje et al., 2020). Accordingly, there is considerable interest in possible preventive or therapeutic treatments. There are several possible targets in the coronavirus life cycle for therapeutic interventions including attachment and entry, uncoating, gRNA replication, translation in endoplasmic reticulum (ER) and Golgi, assembly, and virion release (Guy et al., 2020). Viral attachment and entry are particularly promising as they are the first steps in the replication cycle and take place at a relatively accessible extracellular site; hence, they have been explored for intervention purposes for several viruses (Melby and Westby, 2009). CoVs use their glycosylated spike (S) protein to bind to their cognate cell surface receptors and initiate membrane fusion and virus entry. For both SARS-CoV and SARS-CoV-2, the S protein mediates entry into cells by binding to angiotensin converting enzyme 2 (ACE2) via its receptorbinding domain (RBD) followed by proteolytic activation by human proteases (Lan et al., 2020; Matheson and Lehner, 2020; Shang et al., 2020; Sivaraman et al., 2020). Blockade of this RBD-ACE2 protein-protein 
interaction (PPI) can disrupt infection efficiency; for example, SARS-CoV-2 RBD protein was shown to block S protein mediated SARS-CoV-2 pseudovirus entry into their respective ACE2 receptor-expressing target cells (Tai et al., 2020). Antibodies can be quite effective PPI inhibitors, and they are highly target-specific and relatively stable in vivo. However, they cannot reach intracellular targets and, as all other protein therapies, are hindered by problems such as low solubility, propensity for immunogenicity, long elimination half-lives, lack of oral bioavailability, product heterogeneity, and possible manufacturing and storage stability issues. Since they are foreign proteins, they elicit strong immune response in certain patients (Suntharalingam et al., 2006; Wadman, 2006; Leader et al., 2008), and even if approved for clinical use, they tend to have more post-market safety issues than small-molecule drugs (Downing et al., 2017). Small-molecule inhibitors (SMIs) are more challenging to identify for PPIs, but it is now well established that they can be effective against certain PPIs and can offer useful alternatives. There are now $>40$ PPIs targeted by SMIs that are in preclinical development, and two such SMIs are approved for clinical use (venetoclax and lifitegrast) (Arkin and Wells, 2004; Milroy et al., 2014; Scott et al., 2016; Bojadzic and Buchwald, 2018).

Due to our interest in the chemical space of organic dyes to identify potential SMls for PPIs (Margolles-Clark et al., 2009a; Margolles-Clark et al., 2009b; Ganesan et al., 2011; Song et al., 2014; Chen et al., 2017; Bojadzic and Buchwald, 2018; Bojadzic et al., 2018), we initiated a screen of such compounds for their ability to inhibit the interaction between SARS-CoV-2 spike protein and its cognate receptor ACE2, which is the first critical step initiating the viral attachment and entry of this CoV. As part of this, we found that methylene blue, a tricyclic phenothiazine compound approved for the treatment of acquired methemoglobinemia and some other uses (Clifton and Leikin, 2003; Schirmer et al., 2011; Bistas and Sanghavi, 2020), inhibits this interaction, and we have confirmed that it does so in a concentrationdependent manner. This can contribute to the antiviral activity of this inexpensive and widely available 
dye-based drug against SARS-CoV-2 making it potentially useful in the prevention and treatment of COVID-

19, especially in non-industrialized nations.

\section{MATERIALS AND METHODS}

\section{Binding Assays}

Methylene blue and all other test compounds used here were obtained from Sigma-Aldrich (St. Louis, MO, USA). ACE2-Fc and SARS-CoV-2 S1 or RBD with His tag proteins used in the binding assay were obtained from SinoBiological (Wayne, PA, USA); catalog no. 10108-H05H, 40592-V08H, and 40591-V08H). Binding inhibition assays were performed in a 96-well cell-free format similar to the one described before (Margolles-Clark et al., 2009b; Ganesan et al., 2011; Song et al., 2014; Chen et al., 2017). Briefly, microtiter plates (Nunc F Maxisorp, 96-well; Thermo Fisher Scientific, Waltham, MA, USA) were coated overnight at $4{ }^{\circ} \mathrm{C}$ with $100 \mu \mathrm{L} /$ well of Fc-conjugated ACE2 receptor diluted in PBS pH 7.2. This was followed by blocking with $200 \mu \mathrm{L} /$ well of SuperBlock (PBS) (Thermo Fisher Scientific) for $1 \mathrm{~h}$ at RT. Then, plates were washed twice using washing solution (PBS pH 7.4, 0.05\% Tween-20) and tapped dry before the addition of the tagged ligand (SARS-CoV-2 S1 or RBD) and test compounds diluted in binding buffer (100 mM HEPES, pH 7.2) to give a total volume of $100 \mu \mathrm{L} /$ well. After $1 \mathrm{~h}$ incubation, three washes were conducted, and a further $1 \mathrm{~h}$ incubation with anti-His HRP conjugate diluted (1:2500) in SuperBlock (PBS) was used to detect the bound His-tagged ligand. Plates were washed four times before the addition of $100 \mu \mathrm{L} /$ well of HRP substrate TMB $\left(3,3^{\prime}, 5,5^{\prime}\right.$-tetramethylbenzidine $)$ and kept in the dark for up to $15 \mathrm{~min}$. The reaction was stopped using $20 \mu \mathrm{L}$ of $1 \mathrm{M} \mathrm{H}_{2} \mathrm{SO}_{4}$, and the absorbance value was read at $450 \mathrm{~nm}$. The plated concentrations of ACE2 receptor were $1.0 \mu \mathrm{g} / \mathrm{mL}$ for SARS-CoV-2 RBD and $2.0 \mu \mathrm{g} / \mathrm{mL}$ for SARS-CoV-2 S1. The concentrations of the ligand used in the inhibitory assays were $0.5 \mu \mathrm{g} / \mathrm{mL}$ for RBD and $1.0 \mu \mathrm{g} / \mathrm{mL}$ for S1. These values were selected following preliminary testing to optimize response (i.e., to produce a highenough signal at conditions close to half-maximal response, $\mathrm{EC}_{50}$ ). Binding assessments for $\mathrm{CD} 40-\mathrm{CD} 40 \mathrm{~L}$ 
and TNF-R1-TNF- $\alpha$ were performed as previously described (Bojadzic et al., 2018). Stock solutions of compounds at $10 \mathrm{mM}$ in DMSO were used.

\section{Statistics and Data Fitting}

All binding inhibition and cell assays were tested in at least duplicate per plates, and assays were performed as at least two independent experiments. As before (Ganesan et al., 2011; Song et al., 2014; Chen et al., 2017), binding data were converted to percent inhibition and fitted with standard log inhibitor vs. normalized response models (Buchwald, 2020) using nonlinear regression in GraphPad Prism (GraphPad, La Jolla, CA, USA) to establish half-maximal (median) effective or inhibitory concentrations $\left(E C_{50}, I C_{50}\right)$.

\section{RESULTS}

As part of our work to identify SMIs for co-signaling PPIs that are essential for the activation and control of immune cells, we discovered that the chemical space of organic dyes, which is particularly rich in strong protein binders, can offer a useful starting point. Accordingly, it seemed logical to explore it for possible inhibitors of the SARS-CoV-2 S protein - ACE2 PPI that is an essential first step for the viral entry of this novel, highly infectious coronavirus. As a first step, we explored the feasibility of setting up a screening assays using a cell-free ELISA-type 96-well format similar to those used in our previous works with Fc-conjugated receptors coated on the plate and FLAG- or His-tagged ligands in the solution (Margolles-Clark et al., 2009b; Ganesan et al., 2011; Song et al., 2014; Chen et al., 2017). To establish assay conditions, we first performed concentration-response assessments using such a format with ACE2-Fc and SARS-CoV-2 S1 or RBD with His tag, and they indicated that both bindings follow classic sigmoid patterns with a slightly stronger binding for RBD than S1 (Figure 1). Fitting of data gave median effective concentrations $\left(\mathrm{EC}_{50} \mathrm{~S}\right)$ and hence binding affinity constant $\left(K_{\mathrm{d}}\right)$ estimates of 5 and $13 \mathrm{nM}$, respectively $(127$ and $1008 \mathrm{ng} / \mathrm{mL}$ ) - in good agreement with the specifications of the manufacturer and published values 
that are also in the low nanomolar range (4-90 nM), typically based on surface plasmon resonance (SPR) studies (Sivaraman et al., 2020).

Accordingly, we can use this format for inhibitory screening, and we decided to use hACE2 with SARS-CoV-2 RBD-His, as it showed stronger binding. In fact, this assay setup is very similar to one recently shown to work as a specific and sensitive SARS-CoV-2 surrogate virus neutralization test based on antibody-mediated blockage of this same PPI (CoV-S-ACE2) (Tan et al., 2020). With this setup in our hands, we performed a preliminary screening of representative organic dyes from our in-house library plus a few compounds that are or have been considered of possible interest in inhibiting SAR-CoV-2 by different mechanisms of action, e.g., chloroquine, clemastine, and suramin (Colson et al., 2020; da Silva et al., 2020; Gordon et al., 2020; McKee et al., 2020; Xiu et al., 2020). Screening at $5 \mu \mathrm{M}$ indicated that most have no activity and, hence, are unlikely to interfere with the S-protein - ACE2 binding needed for viral attachment. Nevertheless, some showed activity; those of selected compounds of interest are shown in Figure 2 together with corresponding chemical structures. Erythrosine B (ErB, FD\&C red \#3), an FDA approved food colorant, was included as a possible positive control since we have shown it previously to be a promiscuous PPI inhibitor together with other xanthene dyes (Ganesan et al., 2011), and it indeed showed strong inhibition here. Of particular interest, methylene blue (MeBlu), which has a long history of diverse medical applications (Clifton and Leikin, 2003; Schirmer et al., 2011; Bistas and Sanghavi, 2020), also showed promising inhibitory activity.

Therefore, to confirm its activity, we performed detailed concentration-response assessments as recommended per experimental guidelines in pharmacology and experimental biology (Curtis et al., 2018; Michel et al., 2020). As shown in Figure 3, this confirmed that MeBlu indeed inhibits concentrationdependent manner an estimated $\mathrm{IC}_{50}$ of $3 \mu \mathrm{M}$, whereas chloroquine and suramin show no inhibitory activity in this assay. Chloroquine, an anti-parasitic and immunosuppressive drug primarily used to prevent and treat malaria, was included as it has potential antiviral activity against SARS-CoV-2 (subject 
to controversies) (Colson et al., 2020). Suramin, an antiparasitic drug approved for the prophylactic treatment of African sleeping sickness (trypanosomiasis) and river blindness (onchocerciasis), was incorporated because it was claimed to inhibit SARS-CoV-2 infection in cell culture most likely by preventing binding or entry of the virus (da Silva et al., 2020) (as well as because we found it earlier to inhibit the CD40-CD40L PPI (Margolles-Clark et al., 2009a)). ErB also inhibited with an $\mathrm{IC}_{50}$ of $0.4 \mu \mathrm{M}$, which is consistent with our previous observation of promiscuous PPI inhibition by this compound with a possibly slightly higher activity than found for other PPIs tested before (1-20 $\mu \mathrm{M})$ (Ganesan et al., 2011). Sunset yellow FCF (FD\&C yellow \#6), an azo dye and an FDA approved food colorant included as a possible negative control, indeed showed no inhibitory activity. Since the $\mathrm{IC}_{50}$ obtained for MeBlu here $(3 \mu \mathrm{M})$ is within the range of its circulating levels following normal clinical dosage (e.g., peak blood concentration of $19 \mu \mathrm{M}$ after $500 \mathrm{mg}$ p.o. with an elimination half-life of $\sim 14 \mathrm{~h}$ (Walter-Sack et al., 2009) or trough levels of 6-7 $\mu \mathrm{M}$ in healthy human volunteers following oral doses of $69 \mathrm{mg}$, t.i.d. $=207 \mathrm{mg} / \mathrm{day}$ (Baddeley et al., 2015)), this inhibitory effect on viral attachment can contribute to the possible antiviral activity of MeBlu against SARS-CoV-2 and possibly other ACE2-binding CoVs such as SARS-CoV and the $\alpha$-coronavirus HCoV NL63.

\section{DISCUSSION}

Results here confirm again the usefulness of our strategy to rely on the chemical space of organic dyes, known to contain strong protein binders, as a starting platform to identify SMI scaffolds for PPI inhibition. Using this strategy, we have achieved considerable progress in targeting co-signaling interactions as we have identified the first SMIs for CD40-CD40L (Margolles-Clark et al., 2009b) and OX40OX40L PPIs (Song et al., 2014) as well as the first promiscuous SMIs of PPIs (Ganesan et al., 2011). Organic dyes contain privileged structures for protein binding (Che et al., 2006; Fletcher and Hamilton, 2006; Hershberger et al., 2007), and, contrary to usual drug-like libraries, whose chemical space does not 
correspond well with that of promising PPI inhibitors (Neugebauer et al., 2007; Reynès et al., 2010; Sperandio et al., 2010), they are a good starting point to identify SMIs of PPIs. Most dyes, however, are unsuitable for therapeutic development because of their strong color and, in the case of azo dyes, their quick metabolic degradation (Levine, 1991; Feng et al., 2012); hence further medicinal chemistry is needed to optimize their clinical potential (Chen et al., 2017).

More importantly, our results indicate that MeBlu, an organic dye in clinical use for some therapeutic applications in the developed world (Clifton and Leikin, 2003; Schirmer et al., 2011; Bistas and Sanghavi, 2020) and with additional potential for certain developing world applications such as malaria (Dicko et al., 2018), can inhibit the viral attachment and entry of SARS-CoV-2 by blocking the PPI of its spike protein with ACE2 on the host cell. MeBlu is a tricyclic phenothiazine dye approved by the FDA for clinical use for the treatment of methemoglobinemia, and it is also used for other applications such as prevention of urinary tract infections in elderly patients; ifosfamid-induced neurotoxicity in cancer patients; vasoplegic syndrome, a type of distributive shock that occurs during coronary procedures; and intraoperative visualization of nerves, nerve tissues, and endocrine glands (Schirmer et al., 2011; Bistas and Sanghavi, 2020). MeBlu is included in the WHO List of Essential Medicines and was, in fact, the very first fully synthetic drug used in medicine, as it was used to treat malaria since 1891 (Schirmer et al., 2011). This utilization spanned through WW2 until it was replaced by chloroquine; although, due to the blue urine it could cause, MeBlu was not well liked among the soldiers ("Even at the loo we see, we pee, navy blue") (Schirmer et al., 2011). It also served as the lead compound for the development of chlorpromazine and tricyclic antidepressants (Schirmer et al., 2011). Moreover, there is resurgent interest in its antimalarial application (Dicko et al., 2018), and it has potential for the treatment of neurodegenerative disorders such as Alzheimer's disease (AD), due to its putative inhibitory action on the aggregation of tau protein (Schirmer et al., 2011). Notably, MeBlu was also part of the first method developed for pathogen inactivation in plasma, where it has been used since 1991 to inactivate viruses in combination with light 
(Lozano et al., 2013). MeBlu intercalates within nucleic acid strands, and application of light causes its excitation generating highly reactive singlet oxygen that oxidizes guanosine and breaks nucleic strands (Lozano et al., 2013). Hence, in the presence of light, MeBlu has broad-spectrum virucidal activity and is used to inactivate viruses in blood products prior to transfusions.

Notably, there is also recent evidence of possible in vitro antiviral activity for MeBlu even in the absence of UV-induced activation, as MeBlu showed virucidal activity at low micromolar concentrations when incubated with SARS-CoV-2 for $20 \mathrm{~h}$ in the dark (Cagno et al., 2020). Its ability to inhibit the SARSCoV-2-S - ACE2 PPI could be a mechanism of action contributing to such activity. If this PPI inhibitory activity of MeBlu is retained at similar levels in vivo as found here in a cell-free assay $\left(\mathrm{IC}_{50}=3 \mu \mathrm{M}\right)$, it is within a range that can be obtained in blood following typical doses (e.g., $200 \mathrm{mg} /$ day) as indicated by pharmacokinetic studies in humans. For example, in one study, peak blood concentration of MeBlu was $19 \mu \mathrm{M}$ after $500 \mathrm{mg}$ p.o., and the elimination half-life was also more than adequate being around $14 \mathrm{~h}$ (Walter-Sack et al., 2009). In another study, trough levels of 6-7 $\mu \mathrm{M}$ were obtained following total daily oral doses of $207 \mathrm{mg} /$ day (administered as $69 \mathrm{mg}$, p.o., t.i.d.) (Baddeley et al., 2015). Hence, oral administration could provide adequate concentrations (e.g., > $7 \mu \mathrm{M}$ ) and inhaled applications, which have been explored in less developed countries for some respiratory treatments (Golwalkar, 2020), could be even more advantageous. MeBlu is generally safe, but it shows dose-dependent toxicity with nausea, vomiting, hemolysis, and other undesired side effects starting to occur at doses $>7 \mathrm{mg} / \mathrm{kg}$ (i.e., $>500 \mathrm{mg}$ ) (Clifton and Leikin, 2003; Bistas and Sanghavi, 2020). It also is contraindicated in certain populations, e.g., in those taking serotonin reuptake inhibitors and in persons with hereditary glucose-6-phosphate dehydrogenase deficiency (G6PD deficiency) (Schirmer et al., 2011; Bistas and Sanghavi, 2020).

It has to be noted, however, that MeBlu also inhibited the CD40-CD40L and TNF-R1-TNF $\alpha$ PPIs in our assays with low- to mid-micromolar potency (data not shown); hence, it is possible that MeBlu is a somewhat promiscuous PPI inhibitor limiting its usefulness. Its three-ring phenothiazine framework 
resembles somewhat the three-ring xanthene framework of erythrosine B (Figure 2), which we have shown before to act as promiscuous PPI inhibitor together with some other structural analog xanthene dyes such as rose Bengal and phloxine (Ganesan et al., 2011). MeBlu certainly shows polypharmacology and acts on a multitude of targets (Schirmer et al., 2011); many of these however can have further beneficial effects in COVID-19 patients. Its main mechanism of action is reducing the oxidized ferric form of hemoglobin $\left(\mathrm{Fe}^{3+}\right)$ when in a state of methemoglobinemia, which binds oxygen irreversibly, to the ferrous $\left(\mathrm{Fe}^{2+}\right)$ form (Bistas and Sanghavi, 2020). This increases the oxygen-binding capacity of hemoglobin and, thus, oxygen delivery to tissues - an important benefit for COVID-19 patients. COVID-19 patients often exhibiting low oxygen levels, typically incompatible with life without dyspnea - a phenomenon termed silent hypoxemia (or happy hypoxia in public media) (Tobin et al., 2020). Possibly relevant to this, MeBlu was found to improve hypoxemia and hyperdynamic circulation in patients with liver cirrhosis and severe hepatopulmonary syndrome (Schenk et al., 2000). MeBlu is being used for the treatment of pneumonia and other respiratory ailments in less developed countries with some success (Golwalkar, 2020).

Further, MeBlu was recently shown to block the PD-1-SHP2 PPI, which is downstream from the PD-1-PD-L1 co-signaling PPI, with low micromolar potency and effectively enough to counteract the suppressive activity of PD-1 on cytotoxic T lymphocytes and restore their cytotoxicity, activation, proliferation, and cytokine-secreting activity (Fan et al., 2020). This mechanism of action targeting this cosignaling pathway (PD-1) could contribute to restoring T cell homeostasis and function from exhausted state (Barber et al., 2006; Vardhana and Wolchok, 2020), which is of interest to improve viral clearance and rein-in the inflammatory immune response and the associated cytokine storm during anti-viral responses such as those causing the high mortality of COVID-19 patients (Liu et al., 2020; Ye et al., 2020).

As far as clinical applications, one promising indication comes from a report of a cohort of 2500 French patients treated with MeBlu as part of their cancer care none of whom developed influenza like 
illness during the COVID-19 epidemics (Henry et al., 2020). MeBlu has also been explored in one Phase 1 clinical trial (NCT04370288) for treatment of critically ill COVID-19 patients in Iran as part of a three-drug last therapeutic option add-on cocktail (MeBlu $1 \mathrm{mg} / \mathrm{kg}$, vitamin C $1500 \mathrm{mg} / \mathrm{kg}$, and N-acetyl cysteine 2000 $\mathrm{mg} / \mathrm{kg}$ ) based on the hypothesis that this combination could rebalance NO, methemoglobin, and oxidative stress. Four of the five patients responded well to treatment (Alamdari et al., 2020).

In conclusion, screening of our organic dye-based library identified MeBlu as a low-micromolar inhibitor of the interaction between SARS-CoV-2 spike protein and its cognate receptor ACE2, a PPI that is the first critical step initiating the viral entry of this coronavirus. While MeBlu shows strong polypharmacology and might be a somewhat promiscuous PPI inhibitor, its ability to inhibit this PPI could contribute to the antiviral activity of MeBlu against SARS-CoV-2 even in the absence of light making this inexpensive and widely available drug potentially useful in the prevention and treatment of COVID-19 as an oral or inhaled medication.

\section{ABBREVIATIONS:}

ACE2, angiotensin converting enzyme 2; CoV, coronavirus; MeBlu, methylene blue; PPI, proteinprotein interaction; SARS, severe acute respiratory syndrome; SMI, small-molecule inhibitor.

\section{ACKNOWLEDGEMENTS}

Financial support by the Diabetes Research Institute Foundation (www.diabetesresearch.org) is gratefully acknowledged. 


\section{AUTHOR CONTRIBUTIONS}

DB performed most of the experiments, OA contributed to some. PB originated and designed the project, provided study guidance, and wrote the draft manuscript. All authors contributed to writing and read the final manuscript.

\section{CONFLICTS OF INTEREST}

The authors declare that the research was conducted in the absence of any commercial or financial relationships that could be construed as a potential conflict of interest.

\section{REFERENCES}

Alamdari, D.H., Moghaddam, A.B., Amini, S., Keramati, M.R., Zarmehri, A.M., Alamdari, A.H., et al. (2020). Application of methylene blue -vitamin $\mathrm{C}-\mathrm{N}$-acetyl cysteine for treatment of critically ill COVID19 patients, report of a phase-I clinical trial. Eur. J. Pharmacol., 173494. doi: https://doi.org/10.1016/i.ejphar.2020.173494.

Arkin, M.R., and Wells, J.A. (2004). Small-molecule inhibitors of protein-protein interactions: progressing towards the dream. Nat. Rev. Drug Discov. 3(4), 301-317. doi: https://doi.org/10.1038/nrd1343.

Baddeley, T.C., McCaffrey, J., Storey, J.M., Cheung, J.K., Melis, V., Horsley, D., et al. (2015). Complex disposition of methylthioninium redox forms determines efficacy in tau aggregation inhibitor therapy for Alzheimer's disease. J. Pharmacol. Exp. Ther. 352(1), 110-118.

Barber, D.L., Wherry, E.J., Masopust, D., Zhu, B., Allison, J.P., Sharpe, A.H., et al. (2006). Restoring function in exhausted CD8 T cells during chronic viral infection. Nature 439(7077), 682-687. doi: https://doi.org/10.1038/nature04444.

Bistas, E., and Sanghavi, D. (2020). "Methylene blue," in StatPearls. (Treasure Island (FL)).

Bojadzic, D., and Buchwald, P. (2018). Toward small-molecule inhibition of protein-protein interactions: General aspects and recent progress in targeting costimulatory and coinhibitory (immune checkpoint) interactions. Curr. Top. Med. Chem. 18(8), 674-699. doi: https://doi.org/10.2174/1568026618666180531092503.

Bojadzic, D., Chen, J., Alcazar, O., and Buchwald, P. (2018). Design, synthesis, and evaluation of novel immunomodulatory small molecules targeting the CD40-CD154 costimulatory protein-protein interaction. Molecules 23(5), 1153. doi: https://doi.org/10.3390/molecules23051153. 
Buchwald, P. (2020). A single unified model for fitting simple to complex receptor response data. Sci. Rep. 10(1), 13386. doi: https://doi.org/10.1038/s41598-020-70220-w.

Cagno, V., Medaglia, C., Cerny, A., Cerny, T., Tapparel, C., and Cerny, E. (2020). Methylene blue has a potent antiviral activity against SARS-CoV-2 in the absence of UV-activation in vitro. BioRxiv, 2020.2008.2014.251090. doi: https://doi.org/10.1101/2020.08.14.251090.

Che, Y., Brooks, B.R., and Marshall, G.R. (2006). Development of small molecules designed to modulate protein-protein interactions. J. Comput. Aided Mol. Des. 20(2), 109-130.

Chen, J., Song, Y., Bojadzic, D., Tamayo-Garcia, A., Landin, A.M., Blomberg, B.B., et al. (2017). Smallmolecule inhibitors of the CD40-CD40L costimulatory protein-protein interaction. J. Med. Chem. 60(21), 8906-8922. doi: https://dx.doi.org/10.1021/acs.jmedchem.7b01154.

Clifton, J., 2nd, and Leikin, J.B. (2003). Methylene blue. Am. J. Ther. 10(4), 289-291.

Colson, P., Rolain, J.M., and Raoult, D. (2020). Chloroquine for the 2019 novel coronavirus SARS-CoV-2. Int. J. Antimicrob. Agents 55(3), $105923 . \quad$ doi: https://dx.doi.org/10.1016/j.ijantimicag.2020.105923.

Curtis, M.J., Alexander, S., Cirino, G., Docherty, J.R., George, C.H., Giembycz, M.A., et al. (2018). Experimental design and analysis and their reporting II: updated and simplified guidance for authors and peer reviewers. Br. J. Pharmacol. 175(7), 987-993.

da Silva, C.S.B., Thaler, M., Tas, A., Ogando, N.S., Bredenbeek, P.J., Ninaber, D.K., et al. (2020). Suramin inhibits SARS-CoV-2 infection in cell culture by interfering with early steps of the replication cycle. Antimicrob. Agents Chemother., ePub. doi: https://dx.doi.org/10.1128/AAC.00900-20.

Dicko, A., Roh, M.E., Diawara, H., Mahamar, A., Soumare, H.M., Lanke, K., et al. (2018). Efficacy and safety of primaquine and methylene blue for prevention of Plasmodium falciparum transmission in Mali: a phase 2, single-blind, randomised controlled trial. Lancet Infect. Dis. 18(6), 627-639.

Downing, N.S., Shah, N.D., Aminawung, J.A., Pease, A.M., Zeitoun, J.D., Krumholz, H.M., et al. (2017). Postmarket safety events among novel therapeutics approved by the US Food and Drug Administration between 2001 and 2010. J. Am. Med. Assoc. (JAMA) 317(18), 1854-1863.

Fan, Z., Tian, Y., Chen, Z., Liu, L., Zhou, Q., He, J., et al. (2020). Blocking interaction between SHP2 and PD1 denotes a novel opportunity for developing PD-1 inhibitors. EMBO Mol. Med., e11571. https://doi.org/10.15252/emmm.201911571.

Feng, J., Cerniglia, C.E., and Chen, H. (2012). Toxicological significance of azo dye metabolism by human intestinal microbiota. Front. Biosci. 4, 568-586.

Fletcher, S., and Hamilton, A.D. (2006). Targeting protein-protein interactions by rational design: mimicry of protein surfaces. J. R. Soc. Interface 3(7), 215-233.

Ganesan, L., Margolles-Clark, E., Song, Y., and Buchwald, P. (2011). The food colorant erythrosine is a promiscuous protein-protein interaction inhibitor. Biochem. Pharmacol. 81(6), 810-818. doi: http://dx.doi.org/10.1016/j.bcp.2010.12.020. 
Golwalkar, D. (2020). "Treatment for COVID-19 using methylene blue.", in: Medium. https://medium.com/@dr.deepak.golwalkar/treatment-for-covid-19-using-methylene-blued23fc5a31a4d.

Gordon, D.E., Jang, G.M., Bouhaddou, M., Xu, J., Obernier, K., White, K.M., et al. (2020). A SARS-CoV-2 protein interaction map reveals targets for drug repurposing. Nature. doi: https://doi.org/10.1038/s41586-020-2286-9.

Guy, R.K., DiPaola, R.S., Romanelli, F., and Dutch, R.E. (2020). Rapid repurposing of drugs for COVID-19. Science 368(6493), 829-830. doi: https://doi.org/10.1126/science.abb9332.

Henry, M., Summa, M., Patrick, L., and Schwartz, L. (2020). A cohort of cancer patients with no reported cases of SARS-CoV-2 infection: the possible preventive role of methylene blue. . Substantia 4(1 (Suppl. 1)), 888. doi: https://dx.doi.org/10.13128/Substantia-888.

Hershberger, S.J., Lee, S.G., and Chmielewski, J. (2007). Scaffolds for blocking protein-protein interactions. Curr. Top. Med. Chem. 7(10), 928-942.

Lan, J., Ge, J., Yu, J., Shan, S., Zhou, H., Fan, S., et al. (2020). Structure of the SARS-CoV-2 spike receptorbinding domain bound to the ACE2 receptor. Nature 581(7807), 215-220. doi: https://dx.doi.org/10.1038/s41586-020-2180-5.

Leader, B., Baca, Q.J., and Golan, D.E. (2008). Protein therapeutics: a summary and pharmacological classification. Nat. Rev. Drug Discov. 7(1), 21-39.

Levine, W.G. (1991). Metabolism of azo dyes: implication for detoxication and activation. Drug Metab. Rev. 23(3-4), 253-309.

Liu, P.P., Blet, A., Smyth, D., and Li, H. (2020). The science underlying COVID-19: implications for the cardiovascular system. Circulation 142, 68-78. doi: https://dx.doi.org/10.1161/CIRCULATIONAHA.120.047549.

Lozano, M., Cid, J., and Muller, T.H. (2013). Plasma treated with methylene blue and light: clinical efficacy and safety profile. Transfus. Med. Rev. 27(4), 235-240. doi: https://dx.doi.org/10.1016/i.tmrv.2013.08.001.

Margolles-Clark, E., Jacques-Silva, M.C., Ganesan, L., Umland, O., Kenyon, N.S., Ricordi, C., et al. (2009a). Suramin inhibits the CD40-CD154 costimulatory interaction: a possible mechanism for immunosuppressive effects. Biochem. Pharmacol. 77(7), 1236-1245. doi: http://dx.doi.org/10.1016/j.bcp.2009.01.001.

Margolles-Clark, E., Umland, O., Kenyon, N.S., Ricordi, C., and Buchwald, P. (2009b). Small molecule costimulatory blockade: organic dye inhibitors of the CD40-CD154 interaction. J. Mol. Med. 87(11), 1133-1143. doi: http://dx.doi.org/10.1007/s00109-009-0519-3.

Matheson, N.J., and Lehner, P.J. (2020). How does SARS-CoV-2 cause COVID-19? Science 369(6503), $510-$ 511. doi: https://dx.doi.org/10.1126/science.abc6156. 
McKee, D.L., Sternberg, A., Stange, U., Laufer, S., and Naujokat, C. (2020). Candidate drugs against SARSCoV-2 and COVID-19. Pharmacol. Res. 157, 104859. doi: https://dx.doi.org/10.1016/i.phrs.2020.104859.

Melby, T., and Westby, M. (2009). Inhibitors of viral entry. Handb. Exp. Pharmacol. (189), 177-202. doi: https://doi.org/10.1007/978-3-540-79086-0 7 .

Michel, M.C., Murphy, T.J., and Motulsky, H.J. (2020). New author guidelines for displaying data and reporting data analysis and statistical methods in experimental biology. J. Pharmacol. Exp. Ther. 372(1), 136-147. doi: https://dx.doi.org/10.1124/jpet.119.264143.

Milroy, L.G., Grossmann, T.N., Hennig, S., Brunsveld, L., and Ottmann, C. (2014). Modulators of proteinprotein interactions. Chem. Rev. 114(9), 4695-4748.

Moore, J.B., and June, C.H. (2020). Cytokine release syndrome in severe COVID-19. Science 368(6490), 473-474. doi: https://dx.doi.org/10.1126/science.abb8925.

Neugebauer, A., Hartmann, R.W., and Klein, C.D. (2007). Prediction of protein-protein interaction inhibitors by chemoinformatics and machine learning methods. J. Med. Chem. 50(19), 4665-4668.

Reynès, C., Host, H., Camproux, A.C., Laconde, G., Leroux, F., Mazars, A., et al. (2010). Designing focused chemical libraries enriched in protein-protein interaction inhibitors using machine-learning methods. PLoS Comput. Biol. 6(3), e1000695.

Salje, H., Tran Kiem, C., Lefrancq, N., Courtejoie, N., Bosetti, P., Paireau, J., et al. (2020). Estimating the burden of SARS-CoV-2 in France. Science 369(6500), 208-211. doi: https://dx.doi.org/10.1126/science.abc3517.

Schenk, P., Madl, C., Rezaie-Majd, S., Lehr, S., and Muller, C. (2000). Methylene blue improves the hepatopulmonary syndrome. Ann. Intern. Med. 133(9), 701-706. doi: https://dx.doi.org/10.7326/0003-4819-133-9-200011070-00012.

Schirmer, R.H., Adler, H., Pickhardt, M., and Mandelkow, E. (2011). "Lest we forget you--methylene blue...". Neurobiol. Aging 32(12), 2325 e2327-2316. doi: https://dx.doi.org/10.1016/i.neurobiolaging.2010.12.012.

Scott, D.E., Bayly, A.R., Abell, C., and Skidmore, J. (2016). Small molecules, big targets: drug discovery faces the protein-protein interaction challenge. Nat. Rev. Drug Discov. 15(8), 533-550. doi: https://doi.org/10.1038/nrd.2016.29.

Shang, J., Wan, Y., Luo, C., Ye, G., Geng, Q., Auerbach, A., et al. (2020). Cell entry mechanisms of SARSCoV-2. Proc. Natl. Acad. Sci. U.S.A. 117(21), 11727-11734. doi: https://dx.doi.org/10.1073/pnas.2003138117.

Sivaraman, H., Er, S.Y., Choong, Y.K., Gavor, E., and Sivaraman, J. (2020). Structural basis of the SARS-CoV2/SARS-CoV receptor binding and small-molecule blockers as potential therapeutics. Annu. Rev. Pharmacol. Toxicol., ePub. doi: https://dx.doi.org/10.1146/annurev-pharmtox-061220-093932. 
Song, Y., Margolles-Clark, E., Bayer, A., and Buchwald, P. (2014). Small-molecule modulators of the OX40OX40L costimulatory protein-protein interaction. Br. J. Pharmacol. 171(21), 4955-4969. doi: http://dx.doi.org/10.1111/bph.12819.

Sperandio, O., Reynès, C.H., Camproux, A.C., and Villoutreix, B.O. (2010). Rationalizing the chemical space of protein-protein interaction inhibitors. Drug Discov. Today 15(5-6), 220-229.

Suntharalingam, G., Perry, M.R., Ward, S., Brett, S.J., Castello-Cortes, A., Brunner, M.D., et al. (2006). Cytokine storm in a phase 1 trial of the anti-CD28 monoclonal antibody TGN1412. N. Engl. J. Med. 355(10), 1018-1028.

Tai, W., He, L., Zhang, X., Pu, J., Voronin, D., Jiang, S., et al. (2020). Characterization of the receptor-binding domain (RBD) of 2019 novel coronavirus: implication for development of RBD protein as a viral attachment inhibitor and vaccine. Cell. Mol. Immunol. 17(6), 613-620. doi: https://dx.doi.org/10.1038/s41423-020-0400-4.

Tan, C.W., Chia, W.N., Qin, X., Liu, P., Chen, M.I., Tiu, C., et al. (2020). A SARS-CoV-2 surrogate virus neutralization test based on antibody-mediated blockage of ACE2-spike protein-protein interaction. Nat. Biotechnol., ePub. doi: https://dx.doi.org/10.1038/s41587-020-0631-z.

Tiwari, V., Beer, J.C., Sankaranarayanan, N.V., Swanson-Mungerson, M., and Desai, U.R. (2020). Discovering small-molecule therapeutics against SARS-CoV-2. Drug Discov. Today 25(8), 15351544. doi: https://dx.doi.org/10.1016/j.drudis.2020.06.017.

Tobin, M.J., Laghi, F., and Jubran, A. (2020). Why COVID-19 silent hypoxemia is baffling to physicians. Am. J. Respir. Crit. Care Med. 202(3), 356-360. doi: https://dx.doi.org/10.1164\%2Frccm.2020062157CP.

Vardhana, S.A., and Wolchok, J.D. (2020). The many faces of the anti-COVID immune response. J. Exp. Med. 217(6), e20200678. doi: https://dx.doi.org/10.1084\%2Fjem.20200678.

Wadman, M. (2006). London's disastrous drug trial has serious side effects for research. Nature 440(7083), 388-389.

Walter-Sack, I., Rengelshausen, J., Oberwittler, H., Burhenne, J., Mueller, O., Meissner, P., et al. (2009). High absolute bioavailability of methylene blue given as an aqueous oral formulation. Eur. J. Clin. Pharmacol. 65(2), 179-189. doi: https://dx.doi.org/10.1007/s00228-008-0563-x.

Xiu, S., Dick, A., Ju, H., Mirzaie, S., Abdi, F., Cocklin, S., et al. (2020). Inhibitors of SARS-CoV-2 entry: current and future opportunities. J. Med. Chem., ePub. doi: https://dx.doi.org/10.1021/acs.jmedchem.0c00502.

Ye, Q., Wang, B., and Mao, J. (2020). The pathogenesis and treatment of the 'cytokine storm' in COVID19. J. Infect., ePub. doi: https://dx.doi.org/10.1016/j.jinf.2020.03.037. 


\section{FIGURES}

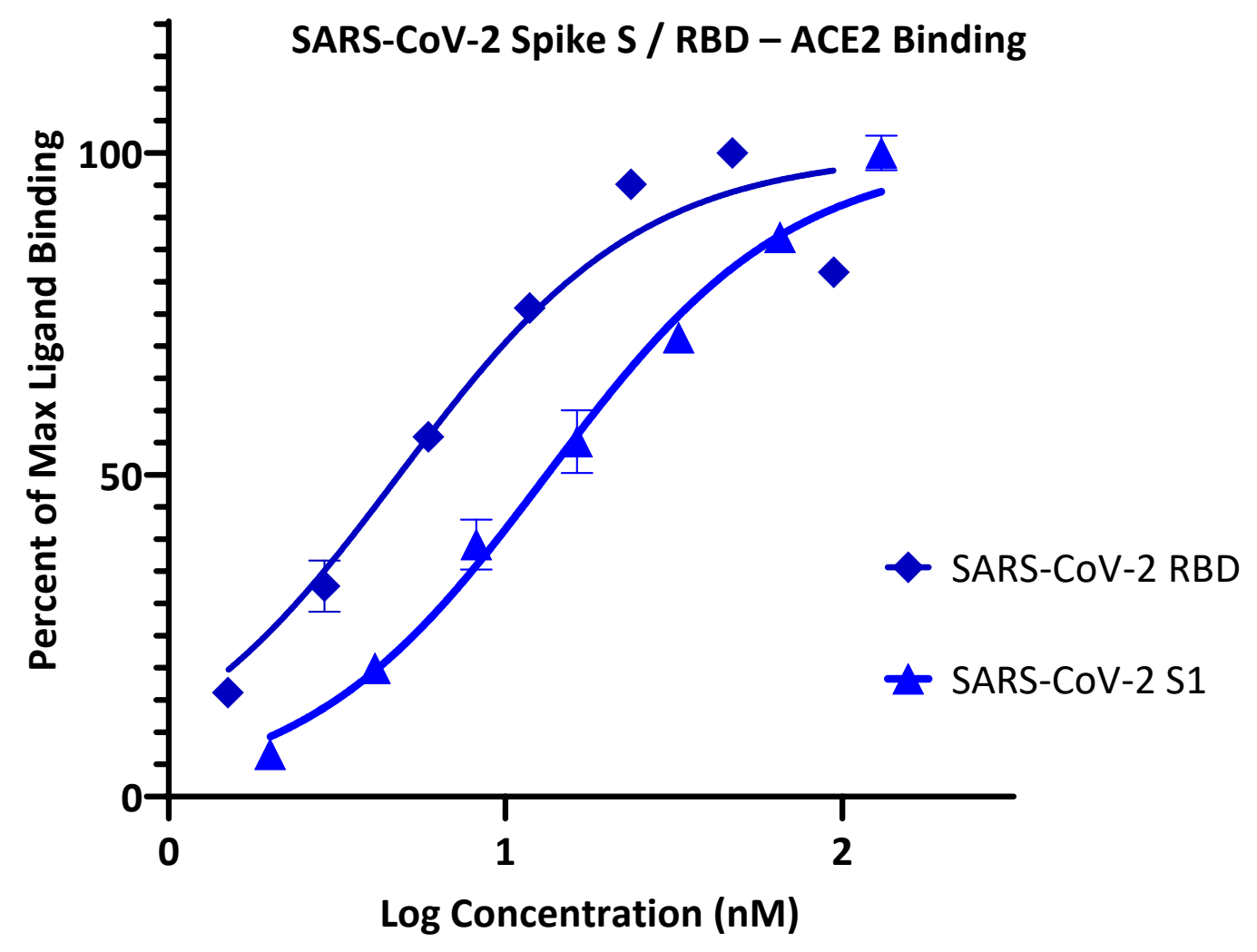

Figure 1. Concentration-response curves for binding of SARS-CoV-2 spike protein S1 and RBD to ACE2 in our ELISA-based assay format. Data obtained with Fc-conjugated ACE2 coated on the plate and Histagged S1 or RBD added in increasing amounts as shown with the amount bound detected using an antiHis-HRP conjugate (mean \pm SD for two experiments in duplicates). 

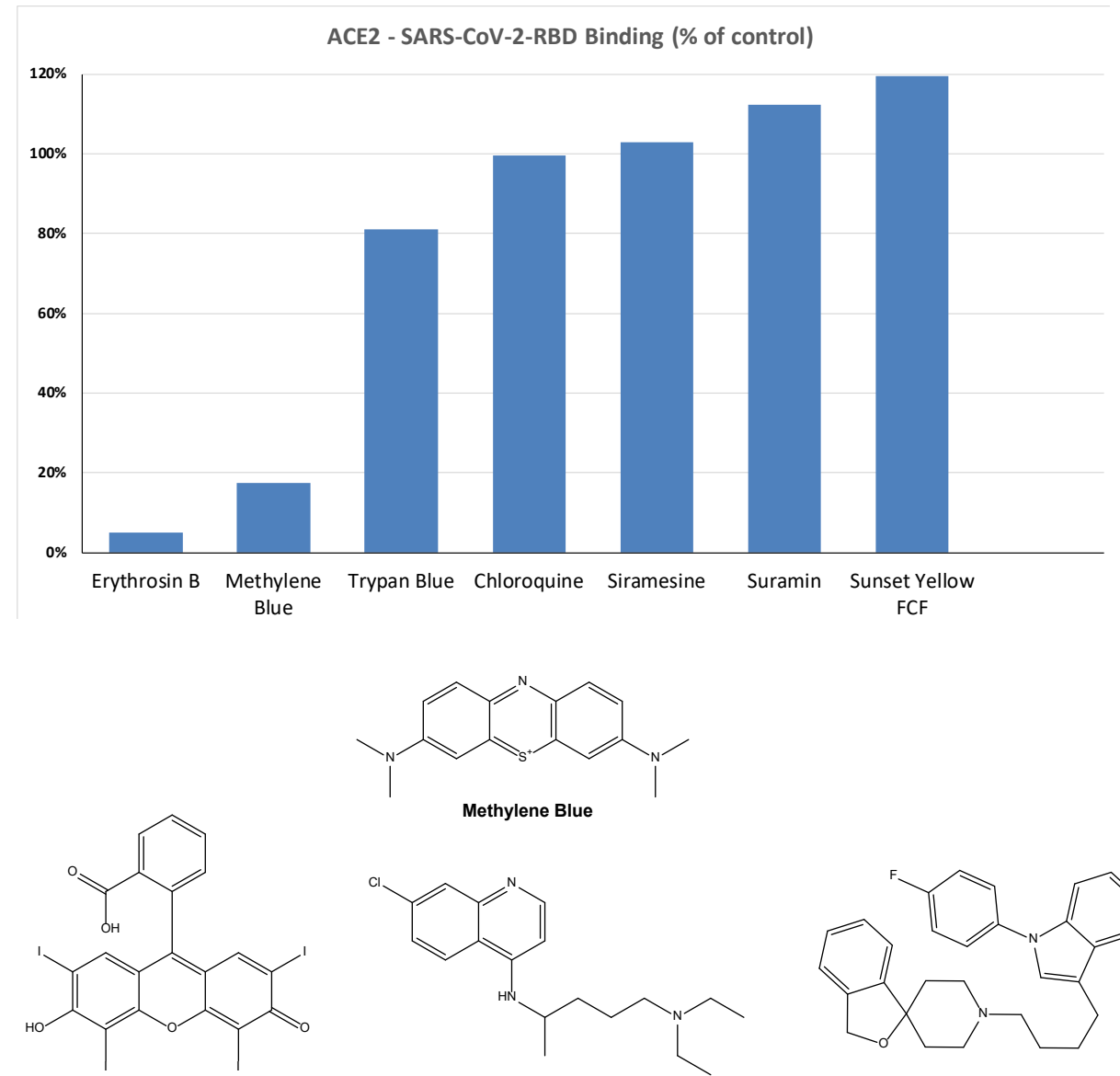<smiles>CN(C)c1ccc2nc3ccc(N(C)C)cc3cc2c1</smiles>

Erythrosin B (FD\&C Red \#3)
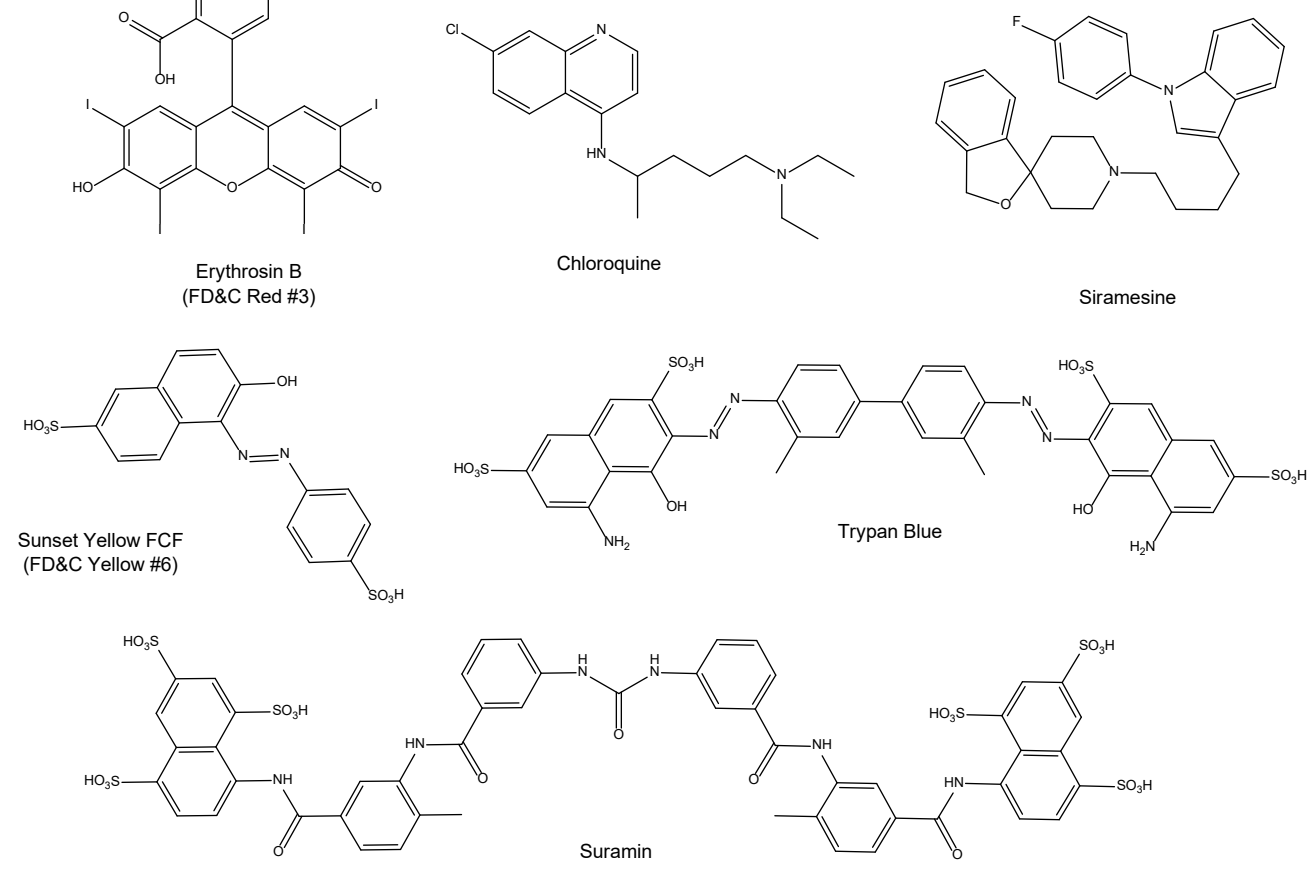

Figure 2. Inhibitory effect of selected compounds on SARS-CoV-2 RBD binding to hACE2 in our screening assay. Percent inhibition values obtained at $5 \mu \mathrm{M}$ concentration shown normalized to control (100\%). Erythrosine B, a known promiscuous SMI of PPIs (Ganesan et al., 2011) and sunset yellow FCF (FD\&C yellow no. 6), a food colorant likely to be inactive, were included as positive and negative controls, respectively. Chemical structures are shown for comparison purposes. 


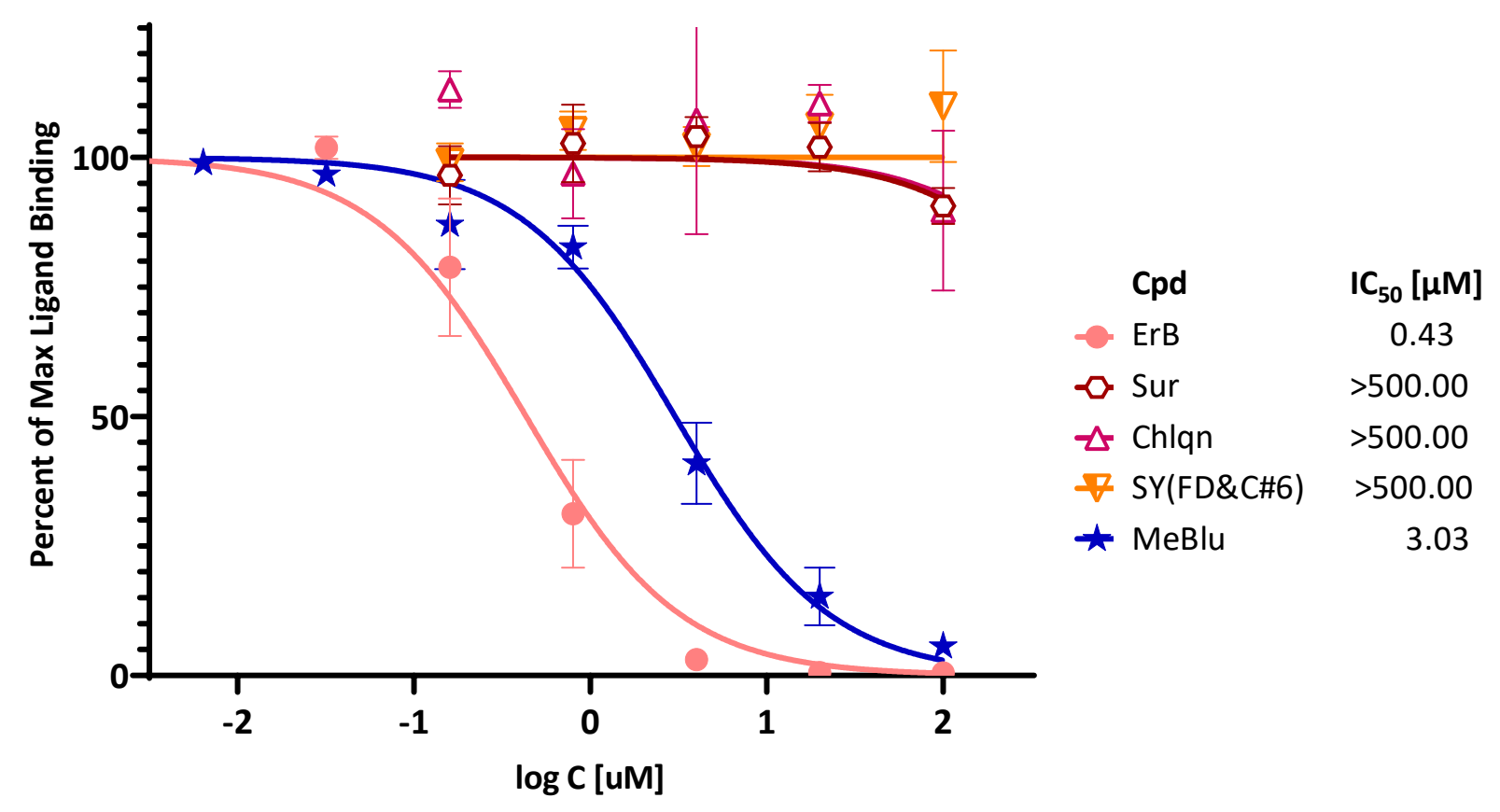

Figure 3. Concentration-dependent inhibition of SARS-CoV-2 RBD binding to ACE2 by selected compounds. Concentration-response curves obtained in ELISA-type assay with Fc-conjugated ACE2 coated on the plate $(1 \mu \mathrm{g} / \mathrm{mL})$ and His-tagged RBD $(0.5 \mu \mathrm{g} / \mathrm{mL})$ added and amount bound in the presence of increasing concentrations of test compounds detected. As before, erythrosine $B(E r B)$ and sunset yellow FCF (SY(FD\&C\#6)) were included as positive and negative controls, respectively. Data (mean \pm SD for two experiments in duplicates) were normalized and fitted with standard inhibition curves; obtained $\mathrm{IC}_{50}$ values are shown at right. 